\title{
Does the relationship between prenatal care and birth weight vary by oral clefts? Evidence using South American and U.S. samples
}

\author{
Kwame A. Nyarko, BA, \\ Doctoral Candidate, Department of Health Management and Policy, University of lowa \\ Jorge Lopez-Camelo, PhD, \\ CEMIC: Centro de Educación Médica e Investigación Clínica; INAGEMP (Instituto Nacional de \\ Genética Médica Populacional) and ECLAMC (Estudio Colaborativo Latino Americano de \\ Malformaciones Congénitas), at Laboratório de Epidemiologia de Malformações Congênitas, \\ Instituto Multidisciplinario de Biologia Celular - IMBICE-CICPBA-CONICET
}

Eduardo E Castilla, MD, PhD, and INAGEMP (Instituto Nacional de Genética Médica Populacional) and ECLAMC (Estudio Colaborativo Latino Americano de Malformaciones Congénitas), at Laboratório de Epidemiologia de Malformações Congênitas, Instituto Oswaldo Cruz, Fundação Oswaldo Cruz, Rio de Janeiro, Brazil, and CEMIC: Centro de Educación Médica e Investigación Clínica

George L. Wehby, PhD Associate Professor, Department of Health Management and Policy, College of Public Health, University of lowa, 105 River Street, N248 CPHB, lowa City, IA 52242, 3193843814 phone, 319 3844371 fax, george-wehby@uiowa.edu

\section{Abstract}

Objective-To evaluate if the association between prenatal care use and birth weight (BW) varies for infants with cleft lip and/or cleft palate (CL/P), classified into isolated and non-isolated forms, compared with unaffected infants.

\begin{abstract}
Study design-The study employed two datasets. The first included a multi-country sample of 2,405 infants with CL/P and 24,046 infants without CL/P born in 1996-2007 in South America. The second was a sample of 2,122 infants with CL/P and 297,415 without CL/P from the United States (U.S.) 2004 Natality dataset. Separate analyses were performed for the South American and U.S. samples. The association between prenatal care and BW was evaluated separately for isolated $\mathrm{CL} / \mathrm{P}$, non-isolated CL/P, and unaffected infants using regression models adjusting for several background characteristics.
\end{abstract}

Results-Prenatal care was associated with improved BW for all infant groups, with greater BW increases for infants with CL/P particularly non-isolated forms. In the South American sample, BW increased by 108,69 , and 40 grams on average per prenatal visit for infants with non-isolated $\mathrm{CL} / \mathrm{P}$, infants with isolated CL/P, and unaffected infants, respectively. In the U.S. sample, BW

\footnotetext{
() 2012 Mosby, Inc. All rights reserved.

Correspondence to: George L. Wehby.

Publisher's Disclaimer: This is a PDF file of an unedited manuscript that has been accepted for publication. As a service to our customers we are providing this early version of the manuscript. The manuscript will undergo copyediting, typesetting, and review of the resulting proof before it is published in its final citable form. Please note that during the production process errors may be discovered which could affect the content, and all legal disclaimers that apply to the journal pertain.

The authors declare no conflicts of interest.
} 
increased by 51, 21, and 16 grams on average per prenatal visit for these infant groups, respectively.

Conclusions-Prenatal care was associated with larger BW increases for pregnancies complicated with CL/P, particularly non-isolated forms, compared with unaffected pregnancies. Given that reduced BW is a well-recognized co-morbidity of CL/P, the findings highlight the importance of prenatal care for at-risk pregnancies as a tertiary-prevention intervention to reduce the health burden of CL/P.

\section{Keywords}

cleft lip; cleft palate; oral clefts; prenatal care; birth weight; infant health

Cleft lip and/or cleft palate (CL/P) are common and burdensome birth defects with a worldwide prevalence of 1 affected birth in 500-2,500 births depending on ancestry and socioeconomic status. [1] In the United States, more than 7000 infants are born with CL/P each year. [2] Much of the complex genetic and environmental etiology remains unknown, [3-5] hindering primary prevention. CL/P are commonly classified into isolated forms without other malformations, and non-isolated forms that involve other malformations.

CL/P impose large burdens on health and wellbeing throughout life. [6] Infants with CL/P have twice as large risk for low birth weight ( $<2500$ grams) as unaffected infants and have lower birth weight by more than 100 and 600 grams with isolated and non-isolated clefts, respectively. [7] [8] CL/P result in feeding problems and ear infections, [9] require surgical interventions, and increase hospitalizations. [10] CL/P also increase infant mortality risks especially in less developed countries. [11] Later in childhood and adolescence, CL/P increase speech problems and behavioral risks due to dissatisfaction with facial appearance and speech. [12, 13] During adulthood, CL/P are associated with reduced education, lower marriage rates, poorer economic performance, [14] increased inpatient mental-health admissions, [15] and higher mortality and suicide risks. [16] The lower BW of infants with $\mathrm{CL} / \mathrm{P}$ compared with unaffected infants highlights a potential pathway for several of the aforementioned effects of CL/P later in life. BW is a strong predictor of future health outcomes and human capital attainment. [17-19] Therefore, part of the adverse health and human capital consequences of CL/P may be due to the lower BW among affected infants.

Prenatal care generally is considered an important intervention for infant health. Several studies report 20-30 gram increase in BW on average per prenatal visit, with larger benefits reported for pregnancies at higher risk for low birth weight. [20-24] However, little is known about how prenatal care affects BW for pregnancies complicated with CL/P, as no previous studies addressed this question.

In this study, we evaluated whether the relationship between prenatal care and BW varies for infants with $\mathrm{CL} / \mathrm{P}$ compared with infants without birth defects. The goal was to assess the utility of enhancing the access of pregnancies at-risk of CL/P to prenatal care as a tertiary prevention of the $\mathrm{BW}$ decrease associated with $\mathrm{CL} / \mathrm{P}$.

\section{Methods}

We separately analyzed two samples in this study. The first sample included 921 infants with non-isolated CL/P, 1,484 infants with isolated CL/P, and 24,046 unaffected infants born between 1996 and 2007 in 111 hospitals in South America (Argentina, Bolivia, Brazil, Chile, Ecuador, Uruguay, and Venezuela). The non-isolated group included infants with CL/ $\mathrm{P}$ who had other birth defects, while the isolated group included infants with only CL/P and no other birth defects. The infants were enrolled through the Latin American Collaborative 
Study of Congenital Malformations (ECLAMC). ECLAMC is a long-standing epidemiological research and surveillance program for birth defects in South America. [20, $23,25]$ ECLAMC is built on voluntary participation of several health professionals (mostly pediatricians) who evaluate all live births in their hospitals and enroll infants born with birth defects into ECLAMC before hospital discharge. ECLAMC professionals obtain health, prenatal, and socioeconomic data from maternal interviews before hospital discharge after delivery and abstract birth records as needed using the same questionnaires and procedures across all hospitals. For each affected infant, ECLAMC professionals enroll an unaffected infant matched by birth date, sex and hospital of birth and obtain similar interview and birth record data as for the affected infants.

The second study sample included 2,122 infants with CL/P - 1,700 isolated and 422 nonisolated cases following the same above-mentioned definitions - and 297,415 unaffected infants from the 2004 U.S. Natality data (most recent dataset with information on state of birth). The unaffected infants were a $10 \%$ random sample of all infants without birth defects in the 2004 Natality dataset, which provided an unbiased estimate of BW mean for children without birth defects in this dataset. The Natality data are compiled by the National Center for Health Statistics based on birth certificates for all live births and include information on pregnancy outcomes, prenatal risk factors, and socioeconomic characteristics. [26]

Our primary measure of prenatal care use was the number of prenatal care visits which is the most commonly used measure in this literature. We evaluated two models for this measure. We first estimated the average effect of a prenatal visit assuming a linear relationship between prenatal care and BW and a similar effect for all visits. Since this assumption may be restrictive, we investigated if the effect varies between visits by estimating a second model that added a squared term of the number of prenatal visits in order to capture if the effect of an additional prenatal care increased or decreased with the visit order. From this second model, we calculated the effect separately for each additional visit (first, second, third, and so on) if prenatal care had a significant non-linear relationship with BW (based on the significance of the squared term). The marginal effect for each visit was calculated by taking the derivative of birth weight with respect to prenatal visits in the regression including prenatal visits and visits squared, and evaluating that derivative for different prenatal visits.

As a sensitivity analysis, we measured prenatal care use by the Kessner Index. [27] This index categorizes prenatal care use into an adequate, intermediate, or inadequate levels depending on the number of prenatal visits, delay in prenatal care initiation, and gestational age at birth using a pre-specified algorithm described in detail elsewhere. [27] Adequate prenatal care is defined as having initiated prenatal care by the $13^{\text {th }}$ gestational week and obtained a minimum number of visits that varies with the gestational age at delivery (e.g. 9 or more visits for delivering at 36 weeks or later). In contrast, prenatal care is considered inadequate if no visits are obtained by the $21^{\text {st }}$ gestational week and only four or fewer visits are obtained by the $34^{\text {th }}$ gestational week.

Our primary model examined the "overall" association between prenatal care and BW due to associating with either fetal growth or gestational age. In a secondary specification, we included gestational age as a covariate in order to isolate the association between prenatal care and BW through fetal growth alone (i.e. conditional on gestational age). We only did this for the models using number of prenatal visits since the Kessner index is already conditioned on gestational age.

We studied the relationship between prenatal care and BW using multivariate regression adjusting for several theoretically relevant characteristics. In addition to theory, we appealed 
to the extensive literature on risk factors for BW for selecting the model covariates. [20, 21, $23,24]$ We adjusted for maternal fertility history, measured by numbers of previous live births and miscarriages/stillbirths, for maternal health measured by indicators for acute and chronic illnesses during pregnancy, and for infant's sex. The model also included maternal age, education, and employment as well as infant race, which captured socioeconomic effects. In the ECLAMC data analysis, we also adjusted for first trimester vaginal bleeding and conception difficulty (unobserved in the Natality data) as additional measures of maternal health problems. Furthermore, we included binary indicators for year and hospital of birth in order to account for time effects and geographic variation in BW and prenatal care. For the Natality data analysis, we adjusted for smoking and marital status during pregnancy (unobserved in ECLAMC data) and included binary indicators for state of birth in order to capture geographic variation in both BW and prenatal care.

We estimated the BW models using ordinary least squares regression that included prenatal care and the above-mentioned covariates and clustered the standard errors at the hospital and state of birth for the ECLAMC and Natality samples, respectively. [30] In order to compare if the association between prenatal care and $\mathrm{BW}$ varied by $\mathrm{CL} / \mathrm{P}$ while avoiding the restrictive assumption that the covariates were similarly associated with $\mathrm{BW}$ regardless of $\mathrm{CL} / \mathrm{P}$ presence and type, we stratified our regression analyses by the following infant groups: 1) infants with non-isolated CL/P; 2) infants with isolated $\mathrm{CL} / \mathrm{P}$; and 3) unaffected infants. We compared the significance of differences in prenatal care coefficients between each of the two affected infant groups ( 1 and 2 ) and unaffected infants using a Chow test. [31]

In the ECLAMC data, the number of prenatal visits for births in certain years (1996-2003 and 2005) was capped during data entry at 9 visits for pregnancies that had more than 9 visits. In other years, that cap was removed. In order to evaluate the sensitivity of the results to that cap, we re-estimated the BW regressions separately for infants born in the uncapped years first without this cap and then adding the cap and compared the estimates between these two models.

Finally, in order to descriptively evaluate the potential bias from self-selection into prenatal care based on unobservable confounders, we performed regression analysis on the number of prenatal visits on all the conceptually relevant background characteristics that were included as covariates in the regression for BW. The goal was to identify any systematic patterns that may suggest selection on unobservable characteristics.

\section{Results}

Tables I and II describe the study variables for the ECLAMC and Natality samples, respectively. The average BW of non-isolated, isolated, and unaffected infants was 2,452, 3,094 and 3,216 grams, respectively, in the ECLAMC sample and 2,684, 3,202, and 3,259 grams, respectively, in the Natality sample. The difference in BW mean between each cleft group and the unaffected infants was significant ( $\mathrm{p}<0.0001$ for all comparisons based on a ttest). The average number of prenatal visits was 6.2 among affected infants and 6.6 for unaffected infants in the ECLAMC sample. In the Natality sample, the average number of prenatal visits was 10.6, 11.6, and 11.4 among infants with non-isolated clefts, isolated clefts, and no clefts, respectively. About $4.3 \%$ of mothers had no prenatal care in the ECLAMC sample, but all mothers in the Natality sample had some prenatal care. Also, about $54.2 \%$ and $24.8 \%$ of ECLAMC sample had intermediate and adequate prenatal care, respectively, based on the Kessner index compared with $19.1 \%$ and $75.5 \%$ in the Natality sample. 
Tables III and IV report the coefficients of prenatal care in the various estimated BW regressions for the ECLAMC and Natality samples, respectively (regression coefficients of all other covariates are in Tables V and VI; available at www.jpeds.com). The results for three regression models with different prenatal care measures include: (1) prenatal visits; (2) prenatal visits and visits squared; and (3) Kessner index. These models were adjusted for the background characteristics described above but not for gestational age. In these models, prenatal visits had significant and positive coefficients for all infants in both the ECLAMC and Natality samples. In several models, the coefficients were significantly larger for infants with CL/P, especially non-isolated forms, compared with unaffected infants.

In the ECLAMC sample, prenatal care visits were associated with an overall BW increase of 108 and 69 grams per visit on average for infants with non-isolated and isolated CL/P, respectively in model 1 (assuming the same effect for each visit). In contrast, an additional prenatal visit was associated with a 40-gram increase in BW on average for unaffected infants in this model. The prenatal visit effects in both groups with CL/P were significantly different from that for unaffected infants. In the second model, the squared term of prenatal visits was insignificant for infants with $\mathrm{CL} / \mathrm{P}$ in the ECLAMC sample suggesting a fairly constant association between prenatal care and BW at each visit for affected infants. In contrast, the squared term had a positive and significant coefficient for the unaffected infants, suggesting an increasing effect for each visit. The effect for unaffected infants ranged from 25 grams increase in BW for the first visit to 48 grams for the $9^{\text {th }}$ visit.

Using model 1 in the Natality sample, prenatal visits were associated with an overall BW increase of 51 and 21 grams per visit on average for infants with non-isolated and isolated $\mathrm{CL} / \mathrm{P}$, respectively, compared with a 16-gram increase for unaffected infants (the effect in the non-isolated group was significantly different from that in the unaffected group). In the second model (assuming a changing effect per visit), each additional prenatal visit had a significantly decreasing effect compared with the previous visit for all three groups (i.e. squared term had a significant negative coefficient). The effect per visit between the $1^{\text {st }}$ and $9^{\text {th }}$ visits ranged from 93 to 67,54 to 33 , and 55 to 32 grams for the non-isolated, isolated, and unaffected infant groups, respectively.

The results using the Kessner Index were generally consistent with those of prenatal visits. Compared with adequate care, no prenatal care was associated with BW decrease of 415 , 383, and 191 grams for non-isolated, isolated, and unaffected infants, respectively, in the ECLAMC sample. Similarly, intermediate care was associated with a larger BW decrease for non-isolated CL/P than isolated CL/P and unaffected infants. However, the differences in care adequacy associations with BW between the three infant groups were not significant. In the Natality sample, intermediate care was associated with BW decrease of 263, 118, and 33 grams for non-isolated, isolated, and unaffected groups, respectively, compared with adequate care. These differences were statistically significant.

Tables III and IV report the prenatal care coefficients in the models that also included gestational age as a covariate. In these models, the coefficients of prenatal visits decreased but remained significant and overall larger for affected infants, although differences between affected and unaffected infants became statistically insignificant. In the ECLAMC sample, prenatal care was associated with increases in fetal growth - i.e. BW adjusted for gestational age - by 33, 32, and 19 grams per visit on average for non-isolated, isolated, and unaffected infants, respectively (based on model 1 assuming a constant effect per visit). In model 2 (allowing for a changing effect per visit), the squared term of prenatal visits was insignificant for all three infant groups, suggesting a fairly constant association between each visit and fetal growth. Using model 1 and the Natality sample, increases in fetal growth were 17, 8 and 5 grams per visit on average for the non-isolated, isolated, and unaffected 
groups, respectively. In model 2, the squared term of visits was negative but significant only for infants with isolated CL/P and unaffected infants.

In the sensitivity analysis of the 9-visit cap data limitation, we found no significant differences in the prenatal care effects between the models that included or removed that cap for the subsample without that limitation (additional information available upon request from the authors). Also, the average number of visits in the capped years was 6.44 compared with 6.88 in the uncapped years.

Finally, the regressions for prenatal care visits on observable background characteristics revealed several significant associations. In both ECLAMC and Natality samples, maternal chronic illness was associated with an increase in prenatal visits, while more previous live births were associated with a decrease in prenatal visits. Similarly, mothers older than 34 years used more prenatal care than those 26-34 years but had lower BW infants. In contrast, mothers 26-34 years used more prenatal care than very young mothers ( 25 years) who had lower BW infants. Higher maternal education was associated with more prenatal visits (additional information available upon request from the authors).

\section{Discussion}

The study finds that the association between prenatal care and BW varies by the presence of $\mathrm{CL} / \mathrm{P}$, with potentially larger benefits to $\mathrm{BW}$ for pregnancies affected with $\mathrm{CL} / \mathrm{P}$ compared with unaffected pregnancies. Furthermore, the association generally is stronger for nonisolated than isolated CL/P forms. Given that infants with CL/P particularly non-isolated forms have significantly lower BW than unaffected infants, the study findings suggest that improving the access of pregnant women at-risk for $\mathrm{CL} / \mathrm{P}$ or who receive a prenatal diagnosis of $\mathrm{CL} / \mathrm{P}$ to prenatal care may play an important role in preventing lower $\mathrm{BW}$ as a co-morbidity of CL/P in affected pregnancies. Since women who themselves have CL/P or who have had a previous child with CL/P have a 40 times higher risk for a subsequent affected child than the general population, [32] these women may especially benefit from earlier and more frequent prenatal care use. The comparisons between the models with and without adjusting for gestational age are consistent with prenatal care improving BW through both gestational length and fetal growth.

One reason for the greater prenatal care benefits for pregnancies affected with CL/P may be that compared with unaffected pregnancies, affected pregnancies especially those with nonisolated (more severe) forms are complicated by more health problems and risk factors that reduce BW and that may be effectively addressed by prenatal care. Indeed, maternal illnesses were more common among pregnancies complicated with $\mathrm{CL} / \mathrm{P}$ than unaffected pregnancies. For example about $47 \%$ and $16 \%$ of mothers of infants with CL/P in the ECLAMC sample had acute and chronic illnesses, respectively, during pregnancy compared with $40 \%$ and $14 \%$ of mothers of unaffected infants. Similarly in the Natality sample, about $15 \%, 9 \%$, and $7 \%$ of mothers in the non-isolated, isolated, and unaffected groups, respectively, had acute illnesses during pregnancy, and about $12 \%$ and $10 \%$ of mothers of affected and unaffected children had chronic illnesses, respectively. Also, smoking rates were higher among mothers of affected than unaffected infants in the Natality sample. Prenatal care may improve BW by identifying and addressing health problems and risk factors. [20, 23]

In this study, we were able to only evaluate the association between prenatal care and BW, and not the causal effects of prenatal care. We adjusted for several maternal characteristics that might relate to self-selection including socioeconomic and demographic factors as well as maternal health and fertility history. However, it is possible that the associations we find 
provide biased estimates of the causal effects of prenatal care. Previous studies generally have suggested that the bias from adverse self-selection into prenatal care (with women at greater risk for lower BW due to unobservable confounders using more prenatal care) dominates the opposite bias from favorable self-selection (women at lower risk for lower BW using more prenatal care). [21] [24] The evidence from these studies would suggest that the reported associations in our study may be underestimates of the real benefits to BW from prenatal care in the study samples. However, we find evidence for both favorable and adverse self-selection into prenatal care based on observable characteristics from the regressions of prenatal care on observable background characteristics. To the extent that self-selection based on observable characteristics reflects selection on unobservable ones, the direction of any potential bias due to unobservable confounders cannot be clearly inferred a-priori based on these analyses. This highlights the need for future studies that can estimate and compare the prenatal care effects between affected and unaffected pregnancies using designs that can account for unobserved confounding bias such as with instrumental variables.

The differences that we find in the prenatal care association with BW between the three infant groups suggest a limited value of indices predefining prenatal care adequacy such as the Kessner index and others as these define adequacy levels based on an underlying assumption of similar prenatal care benefits for all pregnancies. [23] Therefore, the utility of such indices is questionable in the presence of heterogeneity in prenatal care benefits since the adequacy level of prenatal care depends on the benefits of that care and may therefore vary between pregnancy groups that benefit differently from prenatal care. These indices are especially restrictive and less informative than other generic measures such as number of visits for studies such as ours that aim at assessing the value of prenatal care since such assessment would in part define the adequacy level of prenatal care. [28, 29]

The prenatal care visit effects were overall larger in the ECLAMC than the Natality sample. This is in part due to the more frequent use of prenatal care in the Natality sample - on average by about 4 visits - and the diminishing incremental returns with each additional visit (i.e. returns approaching the flat-of-the-curve at higher utilization levels) that we found for the Natality sample. Furthermore, mothers in the ECLAMC sample had higher rates of health problems during pregnancy, with $41 \%$ and $14 \%$ reporting chronic and acute illnesses, respectively, compared with $7 \%$ and $10 \%$ in the Natality sample, respectively. Prenatal care may be associated with larger benefits for more complicated than for less complicated pregnancies. [24] Our sensitivity analysis of the 9-visit cap data limitation suggests that this cap was unlikely to have affected the results significantly. However, this sensitivity analysis was based on a smaller sample than the main analysis. Therefore, the result should be interpreted with this caveat.

In addition to the frequency/intensity of prenatal care use, prenatal care quality may play an important role in BW and possibly to different extents for pregnancies affected with birth defects compared with unaffected pregnancies. However, we observe no direct measures of prenatal care quality in the study data sources and leave this question for future studies. Also, it is possible that the association between prenatal care and BW may vary between infants with different birth defects in the non-isolated group, which would be masked by grouping these infants together. Future studies that evaluate this association separately for more homogenous groups of non-isolated cases that may be defined by the type of other present birth defects such as neural tube defects, congenital heart disease, Down syndrome, and limb defects are important for identifying groups of pregnancies that may benefit differently from prenatal care. Furthermore, extending this work to other types of isolated birth defects such as the aforementioned ones also is important. Finally, future work also is 
needed to understand the pathways that modify the prenatal care association with BW between affected and unaffected pregnancies.

\section{Acknowledgments}

Supported by National Institutes of Health (NIH)/National Institute of Dental and Craniofacial Research (NIDCR) (grant 1R03 DE018394).

\section{References}

1. Mossey PA, Little J, Munger RG, Dixon MJ, Shaw WC. Cleft lip and palate. Lancet. 2009; 374:1773-1185. [PubMed: 19747722]

2. Parker SE, Mai CT, Canfield MA, Rickard R, Wang Y, Meyer RE, et al. Updated National Birth Prevalence estimates for selected birth defects in the United States, 2004-2006. Birth Defects Res A Clin Mol Teratol. 2010; 88:1008-1016. [PubMed: 20878909]

3. Wehby GL, Murray JC. Folic acid and orofacial clefts: a review of the evidence. Oral diseases. 2010; 16:11-19. [PubMed: 20331806]

4. Lidral AC, Moreno LM, Bullard SA. Genetic Factors and Orofacial Clefting. Semin Orthod. 2008; 14:103-114. [PubMed: 19492008]

5. Dixon MJ, Marazita ML, Beaty TH, Murray JC. Cleft lip and palate: understanding genetic and environmental influences. Nat Rev Genet. 2011; 12:167-178. [PubMed: 21331089]

6. Wehby G, Cassell C. The impact of orofacial clefts on quality of life and healthcare use and costs. Oral Dis. 2010; 16:3-10. [PubMed: 19656316]

7. Wyszynski DF, Wu T. Prenatal and perinatal factors associated with isolated oral clefting. Cleft Palate Craniofac J. 2002; 39:370-375. [PubMed: 12019016]

8. Wehby, GL.; Nyarko, KA.; Castilla, EE.; Lopez-Camelo, J. Fetal Structural Shocks and Early Inequalities in Health Capital Accumulation. University of Iowa, Department of Health Management and Policy; 2011.

9. Nackashi, J.; Dedlow, R.; Dixon-Wood, V. Health care for children with cleft lip and palate: comprehensive services and infant feeding. In: DF, W., editor. Cleft Lip and Palate: From Origin to Treatment. New York: Oxford University Press; 2002. p. 127-158.

10. Weiss J, Kotelchuck M, Grosse SD, Manning SE, Anderka M, Wyszynski DF, et al. Hospital use and associated costs of children aged zero-to-two years with craniofacial malformations in Massachusetts. Birth Defects Res A Clin Mol Teratol. 2009; 85:925-934. [PubMed: 19830851]

11. Wehby G, Castilla E, Goco N, Rittler M, Cosentino V, Javois L, et al. The effect of systematic pediatric care on neonatal mortality and hospitalizations of infants born with oral clefts. BMC Pediatrics. 2011; 11:121. [PubMed: 22204448]

12. Kapp-Simon KA, Simon DJ, Kristovich S. Self-perception, social skills, adjustment, and inhibition in young adolescents with craniofacial anomalies. Cleft Palate Craniofac J. 1992; 29:352-356. [PubMed: 1643066]

13. Thomas PT, Turner SR, Rumsey N, Dowell T, Sandy JR. Satisfaction with facial appearance among subjects affected by a cleft. Cleft Palate Craniofac J. 1997; 34:226-231. [PubMed: 9167073]

14. Ramstad T, Ottem E, Shaw WC. Psychosocial adjustment in Norwegian adults who had undergone standardised treatment of complete cleft lip and palate. I. Education, employment and marriage. Scand J Plast Reconstr Surg Hand Surg. 1995; 29:251-257. [PubMed: 8539569]

15. Christensen K, Mortensen PB. Facial clefting and psychiatric diseases: a follow-up of the Danish 1936-1987 Facial Cleft cohort. Cleft Palate Craniofac J. 2002; 39:392-396. [PubMed: 12071787]

16. Christensen K, Juel K, Herskind AM, Murray JC. Long term follow up study of survival associated with cleft lip and palate at birth. BMJ. 2004; 328:1405. [PubMed: 15145797]

17. Currie J. Healthy, Wealthy, and Wise: Socioeconomic Status, Poor Health in Childhood, and Human Capital Development. Journal of Economic Literature. 2009; 47:87-122.

18. Gluckman PD, Hanson MA, Cooper C, Thornburg KL. Effect of in utero and early-life conditions on adult health and disease. N Engl J Med. 2008; 359:61-73. [PubMed: 18596274] 
19. Victora CG, Adair L, Fall C, Hallal PC, Martorell R, Richter L, et al. Maternal and child undernutrition: consequences for adult health and human capital. Lancet. 2008; 371:340-357. [PubMed: 18206223]

20. Wehby GL, Murray JC, Castilla EE, Lopez-Camelo JS, Ohsfeldt RL. Prenatal care demand and its effects on birth outcomes by birth defect status in Argentina. Economics \& Human Biology. 2009; 7:84-95. [PubMed: 19059012]

21. Rosenzweig MR, Schultz TP. Estimating a Household Production Function: Heterogeneity, the Demand for Health Inputs, and Their Effects on Birth Weight. The Journal of Political Economy. 1983; 91:723-746.

22. Warner GL. Birthweight productivity of prenatal care. Southern Economic Journal. 1998; 65:4263.

23. Wehby GL, Murray JC, Castilla EE, Lopez-Camelo JS, Ohsfeldt RL. Prenatal care effectiveness and utilization in Brazil. Health Policy Plan. 2009; 24:175-188. [PubMed: 19282483]

24. Wehby GL, Murray JC, Castilla EE, Lopez-Camelo JS, Ohsfeldt RL. Quantile effects of prenatal care utilization on birth weight in Argentina. Health Economics. 2009; 18:1307-1321. [PubMed: 19142894]

25. Castilla EE, Orioli IM. ECLAMC: the Latin-American collaborative study of congenital malformations. Community Genet. 2004; 7:76-94. [PubMed: 15539822]

26. Taffel SM, Ventura SJ, Gay GA. Revised U.S. certificate of birth--new opportunities for research on birth outcome. Birth. 1989; 16:188-193. [PubMed: 2610783]

27. Kessner, DM. Institute of Medicine (U.S.). Infant death: an analysis by maternal risk and health care. Washington: Institute of Medicine; 1973. Panel on Health Services Research.

28. Kotelchuck M. An evaluation of the Kessner Adequacy of Prenatal Care Index and a proposed Adequacy of Prenatal Care Utilization Index. Am J Public Health. 1994; 84:1414-1420. [PubMed: 8092364]

29. Koroukian SM, Rimm AA. The "Adequacy of Prenatal Care Utilization" (APNCU) index to study low birth weight: is the index biased? J Clin Epidemiol. 2002; 55:296-305. [PubMed: 11864801]

30. White H. A Heteroskedasticity-Consistent Covariance-Matrix Estimator and a Direct Test for Heteroskedasticity. Econometrica. 1980; 48:817-838.

31. Chow G. Tests of Equality Between Sets of Coefficients in Two Linear Regressions. Econometrica. 1960; 38:7.

32. Grosen D, Chevrier C, Skytthe A, Bille C, Molsted K, Sivertsen A, et al. A cohort study of recurrence patterns among more than 54,000 relatives of oral cleft cases in Denmark: support for the multifactorial threshold model of inheritance. J Med Genet. 2010; 47:162-168. [PubMed: 19752161] 
Table 1

Descriptive statistics for the ECLAMC samples

\begin{tabular}{|c|c|c|c|}
\hline & \multicolumn{3}{|c|}{ Percent or Mean (Standard Deviation) } \\
\hline & $\begin{array}{c}\text { Non-isolated } \\
\text { Clefts } \\
(\mathbf{N}=921)\end{array}$ & $\begin{array}{l}\text { Isolated clefts } \\
(\mathrm{N}=1484)\end{array}$ & $\begin{array}{c}\text { No clefts } \\
(\mathrm{N}=24046)\end{array}$ \\
\hline \multicolumn{4}{|l|}{ Variable } \\
\hline \multicolumn{4}{|l|}{ Prenatal care } \\
\hline Number of prenatal care visits (Mean) & $\begin{array}{l}6.18 \\
(2.57)\end{array}$ & $\begin{array}{l}6.20 \\
(2.57)\end{array}$ & $\begin{array}{l}6.57 \\
(2.60)\end{array}$ \\
\hline \multicolumn{4}{|l|}{ Kessner index for prenatal care adequacy (\%) } \\
\hline Adequate prenatal care (reference category) & 21.7 & 23.2 & 25.0 \\
\hline Intermediate prenatal care & 56.9 & 50.5 & 54.3 \\
\hline Inadequate prenatal care & 18.1 & 21.1 & 16.4 \\
\hline No prenatal care & 3.3 & 5.2 & 4.3 \\
\hline \multicolumn{4}{|l|}{ Infant characteristics } \\
\hline Birth weight in grams (Mean) & $\begin{array}{c}2451.89 \\
(882.1)\end{array}$ & $\begin{array}{l}3093.97 \\
(659.42)\end{array}$ & $\begin{array}{l}3216.16 \\
(565.10)\end{array}$ \\
\hline Gestational age in weeks (Mean) & $\begin{array}{l}37.05 \\
(4.18)\end{array}$ & $\begin{array}{l}38.75 \\
(3.05)\end{array}$ & $\begin{array}{l}39.00 \\
(2.71)\end{array}$ \\
\hline \multicolumn{4}{|l|}{ Infant's sex (\%) } \\
\hline Male (reference category) & 50.5 & 58.0 & 54.0 \\
\hline Female & 49.5 & 42.0 & 46.0 \\
\hline \multicolumn{4}{|l|}{ Infant's ancestry (\%) } \\
\hline Other ancestry (reference category) & 13.5 & 14.7 & 12.9 \\
\hline African ancestry & 16.5 & 10.6 & 19.7 \\
\hline Native ancestry & 70.0 & 74.7 & 67.4 \\
\hline \multicolumn{4}{|l|}{ Maternal characteristics } \\
\hline \multicolumn{4}{|l|}{ Conception difficulty $(\%)$} \\
\hline No history of conception difficulty (reference category) & 91.3 & 92.9 & 93.4 \\
\hline History of conception difficulty & 8.7 & 7.1 & 6.6 \\
\hline \multicolumn{4}{|l|}{ Maternal health during pregnancy (\%) } \\
\hline No acute illnesses (reference category) & 53.4 & 52.3 & 59.9 \\
\hline Acute illnesses & 46.6 & 47.7 & 40.1 \\
\hline No chronic illnesses (reference category) & 82.6 & 84.3 & 96.5 \\
\hline
\end{tabular}




\begin{tabular}{|c|c|c|c|}
\hline & \multicolumn{3}{|c|}{ Percent or Mean (Standard Deviation) } \\
\hline & $\begin{array}{c}\text { Non-isolated } \\
\text { Clefts } \\
(\mathbf{N}=921)\end{array}$ & $\begin{array}{l}\text { Isolated clefts } \\
\quad(\mathbf{N}=1484)\end{array}$ & $\begin{array}{c}\text { No clefts } \\
(\mathrm{N}=24046)\end{array}$ \\
\hline Chronic illnesses during pregnancy & 17.3 & 15.6 & 13.5 \\
\hline No vaginal bleeding in 1st trimester (reference category) & 91.2 & 92.8 & 95.0 \\
\hline Vaginal bleeding in 1 st trimester & 8.8 & 7.2 & 5.0 \\
\hline \multicolumn{4}{|l|}{ Pregnancy history (Mean) } \\
\hline Number of previous live births & $\begin{array}{c}1.77 \\
(1.96)\end{array}$ & $\begin{array}{c}1.73 \\
(2.00)\end{array}$ & $\begin{array}{c}1.46 \\
(1.75)\end{array}$ \\
\hline Number of previous spontaneous/stillbirths & $\begin{array}{c}0.328 \\
(0.774)\end{array}$ & $\begin{array}{c}0.263 \\
(0.704)\end{array}$ & $\begin{array}{c}0.195 \\
(0.566)\end{array}$ \\
\hline \multicolumn{4}{|l|}{ Maternal age (\%) } \\
\hline Age 26-34 years (reference category) & 32.5 & 34.3 & 33.1 \\
\hline Age $<20$ years & 17.2 & 19.7 & 21.2 \\
\hline Age $20-25$ years & 31.5 & 32.8 & 34.3 \\
\hline Age $>34$ years & 18.8 & 13.2 & 11.4 \\
\hline \multicolumn{4}{|l|}{ Maternal education (\%) } \\
\hline No schooling, incomplete primary school (reference category) & 23.5 & 20.1 & 23.6 \\
\hline Complete primary school & 23.8 & 23.7 & 20.4 \\
\hline Incomplete secondary school & 22.7 & 25.0 & 25.7 \\
\hline Complete secondary school & 21.1 & 20.6 & 23.1 \\
\hline Incomplete university & 4.8 & 5.7 & 4.1 \\
\hline Complete university & 4.1 & 4.9 & 3.1 \\
\hline \multicolumn{4}{|l|}{ Maternal employment/occupational status (\%) } \\
\hline Unemployed (reference category) & 69.0 & 73.3 & 73.2 \\
\hline Unskilled blue collar & 11.9 & 8.8 & 9.9 \\
\hline Skilled blue collar & 4.1 & 3.7 & 3.8 \\
\hline Independent & 1.8 & 2.0 & 1.6 \\
\hline Clerical positions & 10.4 & 9.1 & 9.2 \\
\hline Professional, boss, executive & 2.8 & 3.1 & 2.3 \\
\hline
\end{tabular}


Table 2

Descriptive statistics for the Natality samples

\begin{tabular}{|c|c|c|c|}
\hline & \multicolumn{3}{|c|}{ Percent or Mean (Standard Deviation) } \\
\hline & $\begin{array}{l}\text { Non-isolated } \\
\text { clefts } \\
(\mathbf{N}=\mathbf{4 2 2})\end{array}$ & $\begin{array}{c}\text { Isolated } \\
\text { clefts } \\
(\mathbf{N}=1,700)\end{array}$ & $\begin{array}{c}\text { No clefts } \\
(\mathbf{N}=\mathbf{2 9 7}, 415)\end{array}$ \\
\hline \multicolumn{4}{|l|}{ Variable } \\
\hline \multicolumn{4}{|l|}{ Prenatal care } \\
\hline Number of prenatal care visits (mean) & $\begin{array}{l}10.61 \\
(4.61)\end{array}$ & $\begin{array}{l}11.56 \\
(4.09)\end{array}$ & $\begin{array}{l}11.43 \\
(4.02)\end{array}$ \\
\hline \multicolumn{4}{|l|}{ Kessner index for prenatal care adequacy ( $\%)$} \\
\hline Adequate prenatal care (reference category) & 67.22 & 73.67 & 75.36 \\
\hline Intermediate prenatal care & 23.35 & 20.82 & 19.09 \\
\hline Inadequate prenatal care & 9.43 & 5.51 & 5.55 \\
\hline No prenatal care & 0 & 0 & 0.003 \\
\hline \multicolumn{4}{|l|}{ Infant characteristics } \\
\hline Birth weight in grams (mean) & $\begin{array}{l}2683.65 \\
(829.93)\end{array}$ & $\begin{array}{l}3202.30 \\
(619.00)\end{array}$ & $\begin{array}{l}3258.89 \\
(616.25)\end{array}$ \\
\hline Gestational age in weeks (mean) & $\begin{array}{l}37.18 \\
(3.53)\end{array}$ & $\begin{array}{l}38.52 \\
(2.58)\end{array}$ & $\begin{array}{l}38.52 \\
(2.58)\end{array}$ \\
\hline \multicolumn{4}{|l|}{ Infant's sex (\%) } \\
\hline Male (reference category) & 48.58 & 57.36 & 52.05 \\
\hline Female & 51.42 & 42.64 & 47.95 \\
\hline \multicolumn{4}{|l|}{ Maternal characteristics } \\
\hline \multicolumn{4}{|l|}{ Marital status (\%) } \\
\hline Unmarried (reference category) & 36.32 & 36.59 & 35.69 \\
\hline Married & 63.68 & 63.41 & 64.31 \\
\hline \multicolumn{4}{|l|}{ Maternal health during pregnancy (\%) } \\
\hline No acute illnesses (reference category) & 84.67 & 91.09 & 92.73 \\
\hline Acute illnesses & 15.33 & 8.91 & 7.27 \\
\hline No chronic illnesses (reference) & 88.44 & 88.15 & 90.27 \\
\hline Chronic illnesses & 11.56 & 11.85 & 9.73 \\
\hline \multicolumn{4}{|l|}{ Pregnancy history (mean) } \\
\hline Number of live births & $\begin{array}{c}1.21 \\
(1.39)\end{array}$ & $\begin{array}{c}1.09 \\
(1.19)\end{array}$ & $\begin{array}{l}1.05 \\
(1.21)\end{array}$ \\
\hline
\end{tabular}




\begin{tabular}{|c|c|c|c|}
\hline & \multicolumn{3}{|c|}{ Percent or Mean (Standard Deviation) } \\
\hline & $\begin{array}{l}\text { Non-isolated } \\
\text { clefts } \\
(\mathbf{N}=\mathbf{4 2 2})\end{array}$ & $\begin{array}{c}\text { Isolated } \\
\text { clefts } \\
(\mathbf{N}=1,700)\end{array}$ & $\begin{array}{c}\text { No clefts } \\
(\mathrm{N}=297,415)\end{array}$ \\
\hline Number of spontaneous stillbirths & $\begin{array}{c}0.47 \\
(0.97)\end{array}$ & $\begin{array}{c}0.42 \\
(0.87)\end{array}$ & $\begin{array}{c}0.38 \\
(0.82)\end{array}$ \\
\hline \multicolumn{4}{|l|}{ Maternal age $(\%)$} \\
\hline Age 26-34 years (reference category) & 41.27 & 41.24 & 44.78 \\
\hline Age $<20$ years & 9.91 & 10.67 & 10.45 \\
\hline Age $20-25$ years & 30.66 & 36.30 & 30.94 \\
\hline Age $>34$ years & 18.16 & 11.79 & 13.83 \\
\hline \multicolumn{4}{|l|}{ Maternal race $(\%)$} \\
\hline Other race (reference category) & 5.9 & 6.69 & 5.98 \\
\hline Black race & 9.67 & 7.62 & 16.12 \\
\hline White race & 84.43 & 85.69 & 77.90 \\
\hline \multicolumn{4}{|l|}{ Maternal behavior during pregnancy (\%) } \\
\hline No smoking (reference category) & 85.85 & 82.82 & 89.71 \\
\hline Smoking during pregnancy & 14.15 & 17.18 & 10.29 \\
\hline \multicolumn{4}{|l|}{ Maternal education (\%) } \\
\hline Incomplete secondary school (reference category) & 23.83 & 23.11 & 20.79 \\
\hline Complete secondary school & 30.66 & 34.84 & 30.13 \\
\hline Incomplete university & 21.93 & 20.76 & 21.51 \\
\hline Complete university & 23.58 & 21.29 & 27.57 \\
\hline
\end{tabular}




$$
\begin{aligned}
& \text { 泀 } \\
& \text { ( } \\
& \text { 인 }
\end{aligned}
$$

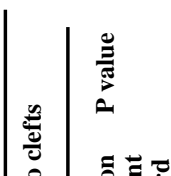

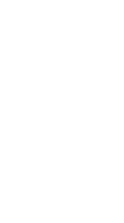

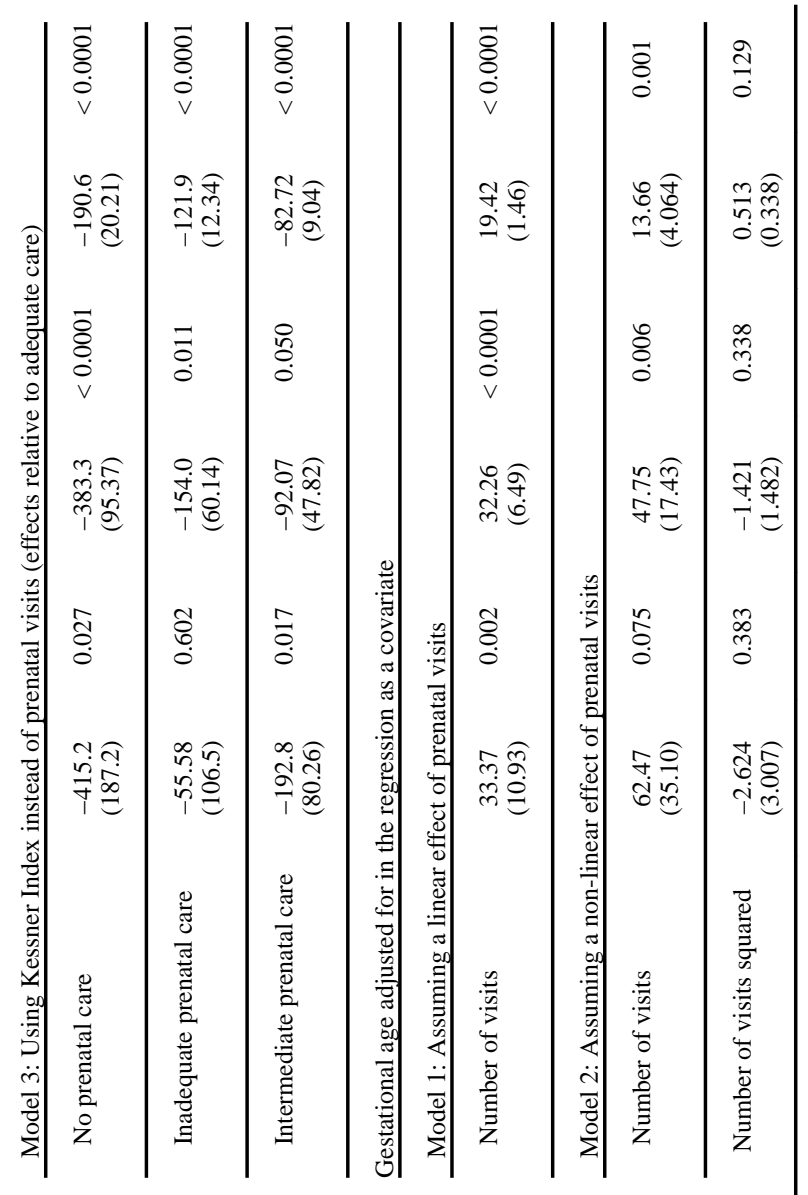




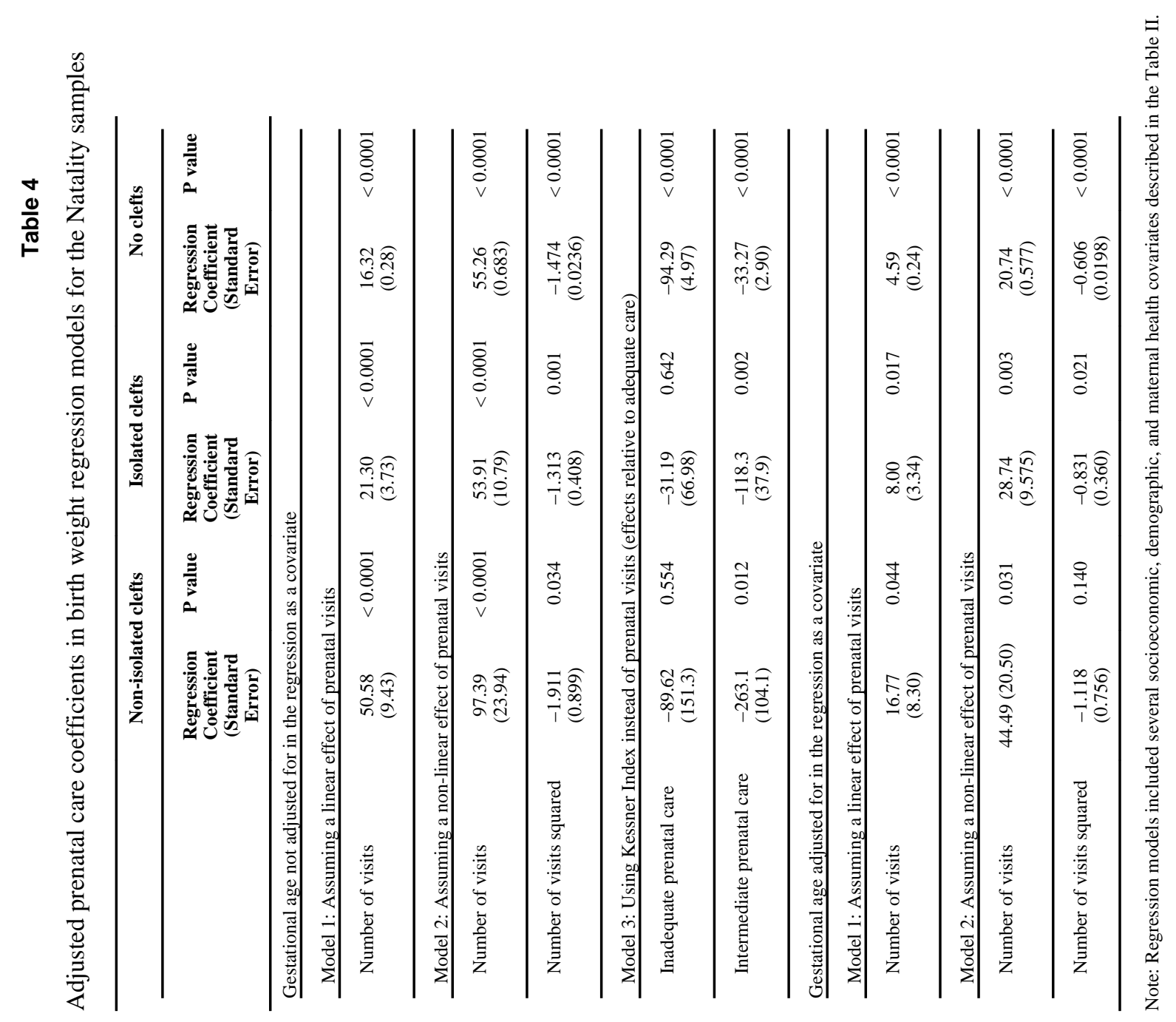




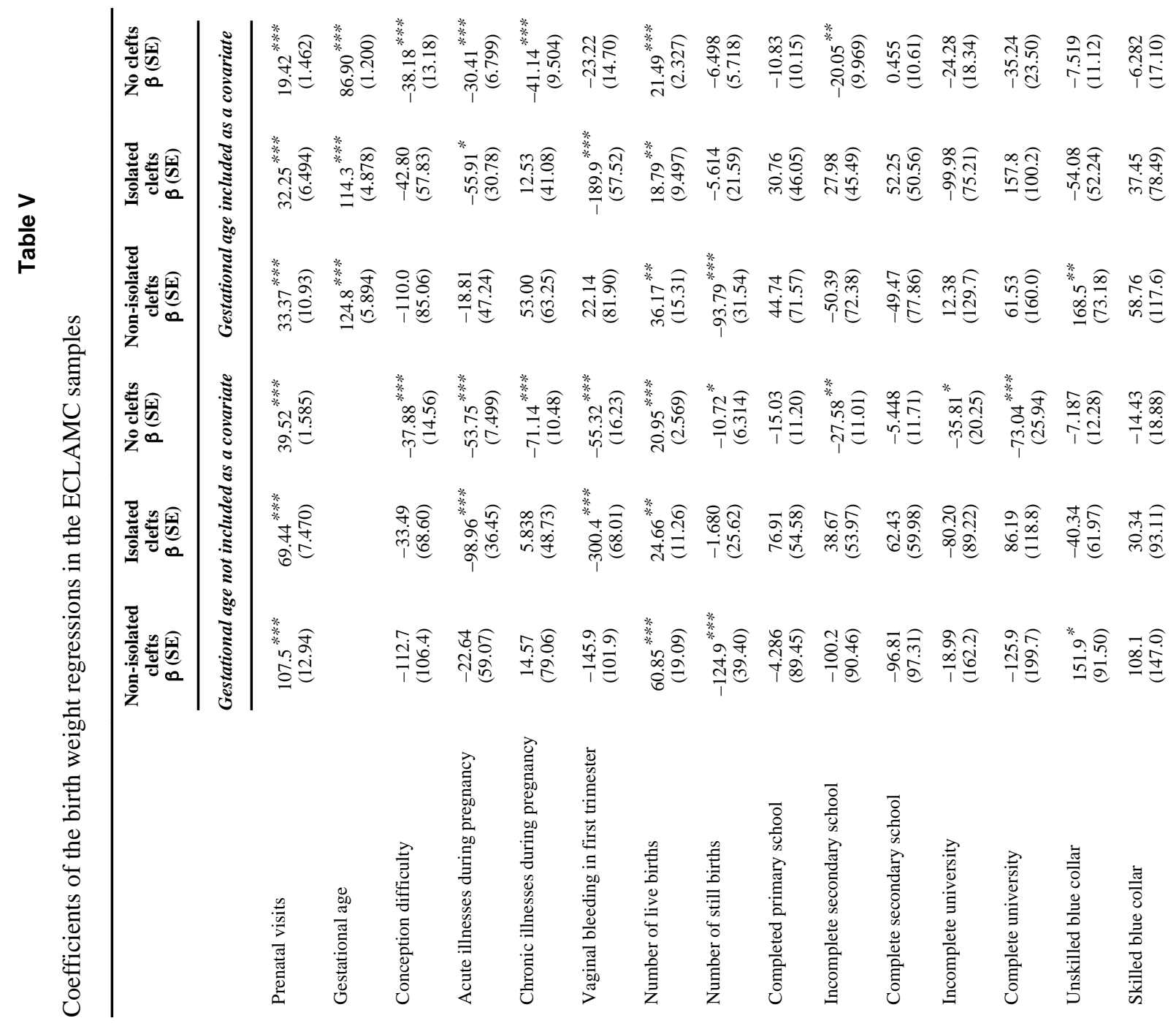




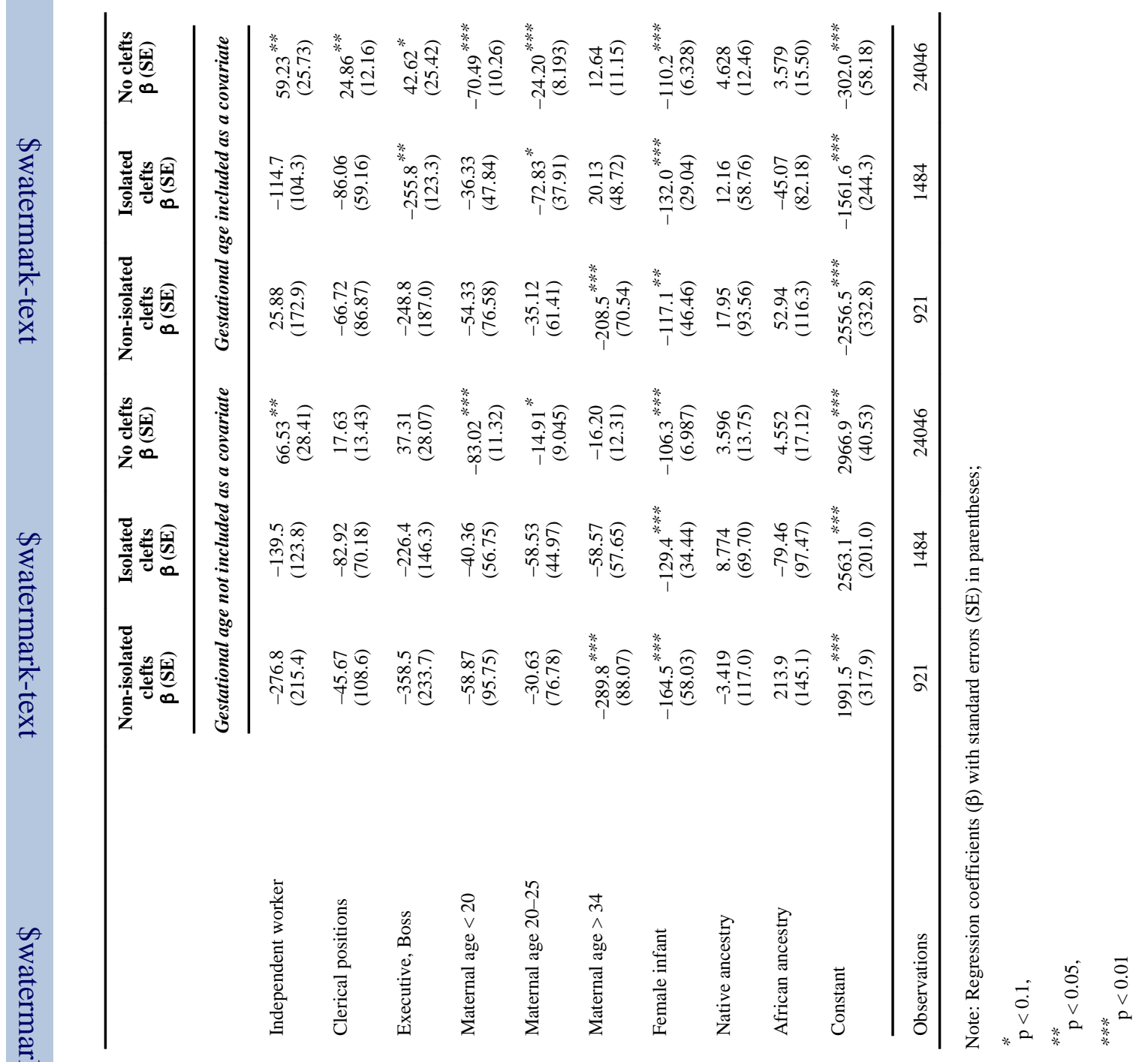




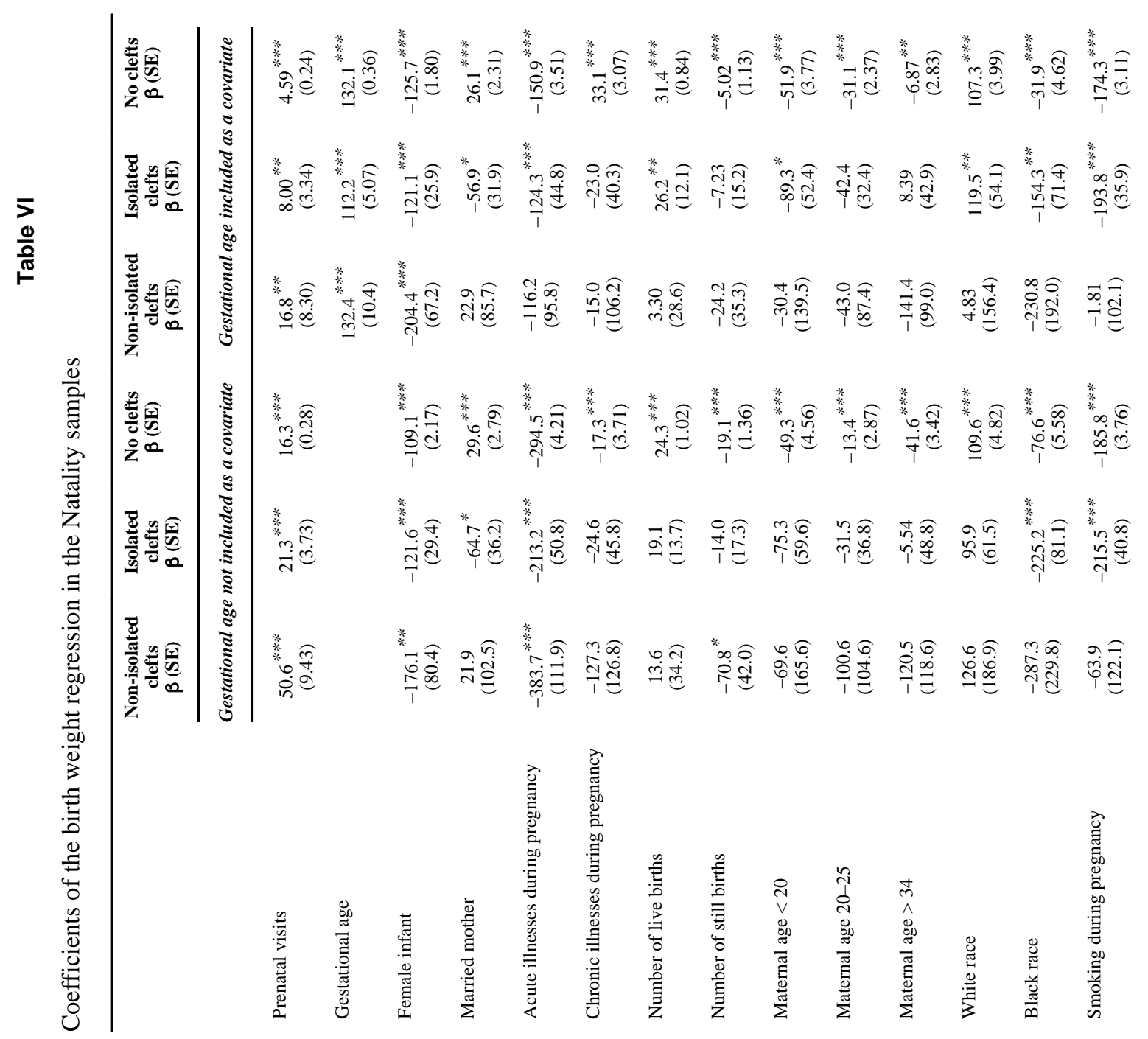




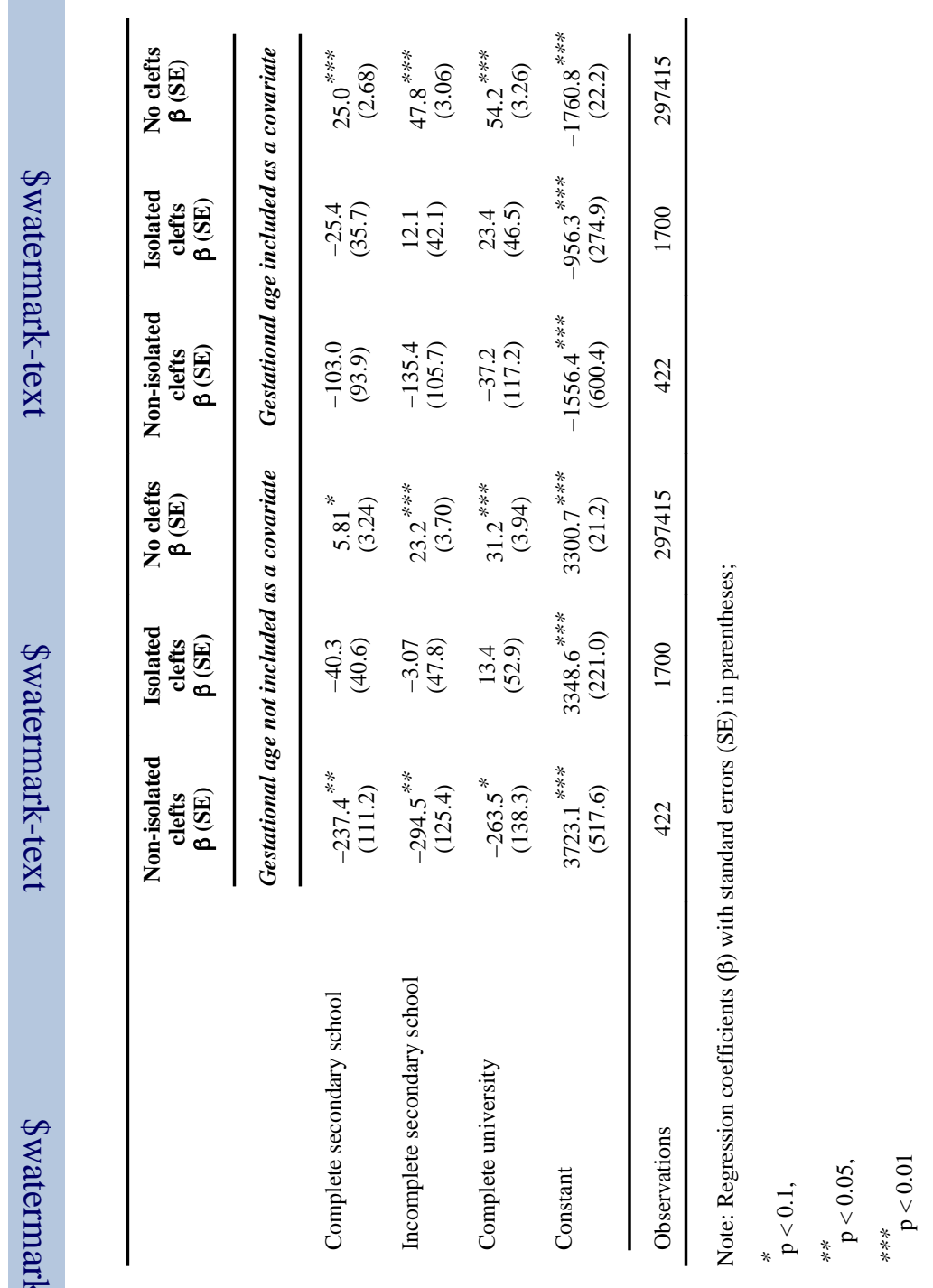

